\title{
Kütahya-Simav jeotermal sularıyla emprenyeli çam odunlarının çekme ve şişme özellikleri ile kullanım yeri stabilitesi
}

\author{
Ahmet Ali Var*,a , Ibrahim $\operatorname{Kardaş}^{\mathrm{a}}$
}

\begin{abstract}
Özet: Bu çalışmada, üç farklı jeotermal kaynak suyunun, iki farklı çam odununun çekme ve şişme özellikleri ile kullanım yeri stabilitesine etkileri açısından değerlendirilmesi amaçlanmıştır. Araştırmada, Kütahya-Simav jeotermal sahasından Naşa (N-1), Çitgöl (Ç-1) ve Eynal (E-6) jeotermal kaynak suları, kızılçam (Pinus brutia Ten.) ve karaçam (Pinus nigra Arnold.) odun örneklerine batırma yöntemiyle uygulanmıştır. Emprenye işlemi ve testler, laboratuvarda normal şartlarda gerçekleştirilmiştir. Sonuçlar göstermiştir ki, jeotermal sularla emprenyede, test örneklerinin radyal, teğet, hacimsel ve anizotropik çekme ve şişme değerleri azalmıştır. Bu azalmalar, jeotermal suların kızılçam ve karaçam odunlarının çalışma özellikleri ve kullanım yeri stabilitelerini iyileştirdiğini göstermektedir. Bu iyileşmelerin, E-6 için diğer jeotermal sulara göre daha fazla olduğu gözlenmiştir. Anahtar kelimeler: Odun, Jeotermal, Emprenye, Çekme, Şişme, Stabilite
\end{abstract}

\section{Shrinking and swelling properties and stability of use place in pine woods impregnated with geothermal waters of Simav, Kütahya, Turkey}

\begin{abstract}
The purpose of this study is to evaluate the effects of three different geothermal resource water shrinking and swelling properties and stability of use place on two different pine wood. This study used sapwood samples of Turkish red pine (Pinus brutia Ten.) and Crimean pine (Pinus nigra Arnold.), dipping method, and Naşa (N-1), Çitgöl (Ç-1) and Eynal (E-6) geothermal waters from Simav, Kütahya, Turkey. The impregnation procedures and tests were carried out under normal conditions in the laboratory. Results showed that the geothermal waters significantly decreased values of radial, tangential, volumetric and anisotropic shrinking and swelling of treated wood samples compared to untreated wood samples. These reductions showed that the shrinkage and swelling properties and stability of use place in pine wood samples were improved by geothermal waters in comparison to untreated wood samples. It was observed that these improvements were higher than other geothermal waters for the E6.

Keywords: Wood, Geothermal, Impregnation, Shrinking, Swelling, Stability
\end{abstract}

\section{Giriș}

Ülkelerin gelişmişlik düzeyi ve artan nüfusuna bağlı olarak, odun esasli yapısal malzemelere olan talepler artmaktadır. Ancak üretim artışı, talep edilen miktarı karşılayamadığı için hammadde odun açığı giderek artmaktadır. Bu açığı kapatmanın akla en uygun yollarından biri, onu en ideal ve rasyonel şekilde değerlendirip kullanmaktır. Böyle bir kullanım, oduna dayalı yapısal malzemelerin faydalı özelliklerini koruyup sakıncalı özelliklerini iyileştiren ahşap emprenye maddelerinin ve bu maddelerin etki düzeylerinin bilinmesiyle mümkün olabilir.

Son yıllarda, dünya genelinde gittikçe artan sağlik ve çevresel sorunlara dayalı baskılardan dolayı, ahşap emprenye maddeleri kullanımında doğal, yenilenebilir, çevre dos tu kimyas al maddeler tercih edilmektedir (Bozkurt vd., 1993). Ayrıca kirletici etkenleri sınırlandırıp denetim altına alabilmek için tercih edilen doğal kaynaklardan birinin de jeotermal sular olduğu belirtilmektedir (Mutlu, 2004).

Jeotermal sular, tabiatın sunduğu yenilenebilen önemli kaynaklardan biridir. $\mathrm{Bu}$ kaynaklar, yüksek oranda çözünmüş zengin kimyasal maddeler ve mineral tuzlar içermekte, sicaklıklarına göre farklı alanlarda değerlendirilmektedir. Bu bakımdan, kullanımları sanayiden tarım, hayvancıllk ve tıbbi tedaviye kadar önemli ölçüde genişlemiştir (Gürü, 2005). Bunların ekonomik olarak işletilebilmesi için, sahip oldukları bütün özelliklerinin doğrudan/dolaylı olarak değerlendirilmesi gerekmektedir (Mutlu, 2004). Bu kaynaklar planlı programlı bir şekilde işletilebildiği takdirde, elde edilecek ürünlerin de sürdürülebilirliği sözkonusu olmaktadır. Ancak bunların büyük bir kısmı henüz endüstride tam olarak kullanılamamaktadır (Gürü, 2005).

Jeotermal kaynakların kullanılmadığı endüstrilerden biri de ahşap koruma sektörüdür. Bu sektöre yönelik olarak, jeotermal kaynakların emprenye maddesi potansiyeline ilaveten odun esas lı yapısal malzemelerin özellikleri üzerine etkilerinin araștırılması da gerekmektedir. Bunların belirlenmesi, çevre dostu doğal bir kaynağın, emprenye maddesi olarak taşıması gereken niteliklerin ortaya konması bakımından önemlidir. Ancak jeotermal suların, bahs edilen bu özelliklerini inceleyen çalışmalar sınırlıdır. $\mathrm{Bu}$ çalışmalardan bazıları şunlardır; jeotermal akışkanlarda

\footnotetext{
\ a Süleyman Demirel Üniversitesi, Orman Fakültesi, Orman Endüstri Mühendisliği Bölümü, Isparta

@ * Corresponding author (İletişim yazarı): alivar@sdu.edu.tr

$\checkmark$ Received (Geliş tarihi): 01.04.2016, Accepted(Kabul tarihi): 28.07.2016
}

Citation (Atıf): Var, A.A., Kardaş, İ., 2017. Kütahya-Simav jeotermal sulariyla emprenyeli çam odunlarının çekme ve şişme özellikleri ile kullanım yeri stabilitesi. Turkish Journal of Forestry, 18(1): 57-62

DOI: $10.18182 / \mathrm{tiff} .308993$ 
ahşap emprenye maddesi potansiyeli (Var, 2009), jeotermal bölgesel 1sitma sistemlerinin ekonomik değerlendirmesi (Erdoğmuş vd., 2006), jeotermal bölgesel isitma sistemlerinin performansı (Özgener vd., 2006), Uşak yöresi jeotermal akışkanlarıyla emprenyeli ahşabın performansı (Karademir, 2012), jeotermal akışkanların antifungal aktivitesi (Var vd., 2012), Afyonkarahisar-Ömer-Gecek jeotermal sularıyla işlem görmüş ahşabın bazı özellikleri (Genç, 2013), İzmir-Doğanbey jeotermal sulariyla emprenyeli kızılçam odununda absorpsiyon, retensiyon ve genişleme (Var vd., 2013), Afyonkarahisar bölgesi jeotermal suları ile emprenyeli çam diri odunlarının bazı özellikleri (Var vd., 2014), Türkiye jeotermal kaynakları envanteri (Akkuş vd., 2005). Diğer yandan, ağaç malzemenin çekme ve şişme özelliklerini inceleyen öne çıkmış pek çok çalışmadan bazıları şunlardır; buharlanmış ağaç malzemenin özellikleri (Kubler, 1978), sığla odununun fiziksel ve mekanik özellikleri (Bozkurt vd., 1990), kereste kurutma ve buharlama (Kantay, 1993), halep çamı odunun fiziksel ve mekaniksel özelliklerinin belirlenmesi (Erten ve Sözen, 1996), Türkiye'de yetişen endüstriyel öneme sahip ağaçların anatomik, fiziksel, mekanik ve kimyasal özellikleri (As vd., 2001), masif ahşap döşemelerde duvar dibi genişleme boşluklarını etkileyen faktörler (Kantay ve Güngör, 2009), toros sediri odunun bazı fiziksel ve mekanik özellikleri (Bal vd., 2012).

Kimyasal madde ve mineral tuz çeşidi bakımından çok zengin olan jeotermal sular, suda çözünen emprenye maddeleri kapsaminda farklı kimyasal tuzlar/mineraller içermektedir (Var, 2009). Bu bağlamda, Kütahya-Simav yöresi jeotermal kaynak suları incelendiğinde, kimyasal madde ve mineral tuz çeşitleri ve derişimleri bakımından zengin oldukları anlaşılmaktadır (Çağlar, 1948; Öktü, 1984; Erişen vd. 1996; Bayram 1999; Akkuş vd. 2005; Özalp ve Ordu, 2010). Diğer yandan, ağaç malzeme emprenyesinde kullanılacak kimyasal maddeye karar verilmeden önce, o maddenin dayanma süresi ile derişiminin ve uygulanacak yöntemin belirlenmesi önemlidir (Bozkurt vd., 1993). Bu durumda, jeotermik maddelerin, ağaç malzemenin çekme ve şişme özellikleri ile kullanım yeri stabilitesini etkilemeleri beklenebilir. Ancak bu etkinin, emprenyesiz örneklere göre ne derece etkili olup olmadığının bilinmesi de önemlidir.

Günümüze kadar yapılan birçok çalışmada yerli çam türü ağaçlarımızın odunlarının daralma ve genișleme özellikleri belirlenmiştir. Ancak kimyasal madde ve mineral tuz çeşidi bakımından zengin olmasına karşılık, Simav yöresi jeotermal kaynak sularının, bu çam odunlarının çalışma özelliği ve kullanım yeri stabilitesi üzerine etkilerinin belirlenmesine yönelik bir araştırma bulunmamaktadır. Bu nedenle, bu makalede, sözkonusu yöreden alınan jeotermal suların, yerli çam odunlarının çalışma özellikleri ve kullanım yeri stabilitesine etki düzeylerinin araştırılması amaçlanmıştır. Makale, bu boşluğu doldurmakla beraber, doğal yenilenebilir bir kaynağın, yerli çamlarımızdan elde edilen ağaç malzemelerin çalışma özelliklerini ve kullanım yeri stabilitelerini ne derece etkilediğinin belirlenmesi, benzer konularda yapılacak araştırmalar ve literatüre katkı sağlaması bakımından önem taşımaktadır.

\section{Materyal ve yöntem}

\subsection{Deneysel materyal ve emprenye işlemi}

Çalışmada, odun materyali olarak, kızılçam (Pinus brutia Ten.) ve karaçam (Pinus nigra Arnold.) odunlanı kullanılmıştır. Deneyler için, sağlam, düzgün lifli ve budaksız seçilen örnekler diri odun kıs mından radyal yönde alınmıştır. Her test için 20 x 20 x $30 \mathrm{~mm}$ ebadında 15'er adet örnek kullanılmıştır. Emprenye materyali olarak, Kütahya-Simav yöresi jeotermal alanından, Eynal (E-6), Çitgöl (Ç-1) ve Naşa (N-1) olmak üzere, üç farkl jeotermal kaynak suyu kullanılmıştır. Kaynaklardan sıcak/kızgın alınan jeotermal sular, normal hava koşullarında oda sicaklığına kadar soğuduktan sonra, emprenye işlerinde kullanılmıştır. Emprenye işleri, laboratuvarda normal hava şartlarında gerçekleştirilmiştir (TS EN 47, 2011). Bu işlemde, odun örnekleri jeotermal su içine en fazla 24 saat batırılmıştır. Emprenyeden sonra, bütün örnekler, en az iki hafta bekletildikten sonra, çekme ve şişme özellikleri ile kullanım yeri stabiliteleri test edilmiştir.

\subsection{Radyal, teğet ve hacimsel çekme}

Radyal ve teğet yönlerdeki çekmeler TS 4083 (1983)'e uyularak tayin edilmiştir. Hacims el çekme tayininde radyal ve teğet yönlerdeki çekme deneyine ilişkin değerlerden yararlanılmıştır. Bu değerler kullanılarak hacimsel çekme TS 4085 (1983)'e göre tayin edilmiştir. Hesaplamada boyuna yöndeki çekmeler dikkate alınmamıştır.

\subsection{Radyal, teğet ve hacimsel şişme}

Radyal ve teğet yönlerdeki şişmeler TS 4084 (1983)'e uyularak tayin edilmiştir. Hacims el şişme tayininde radyal ve teğet yönlerdeki şişme deneyine ilişkin değerlerden yararlanılmıştır. Bu değerler kullanılarak hacimsel şişme TS 4086 (1983)'ya göre tayin edilmiştir. Hesaplamada boyuna yöndeki şişmeler dikkate alınmamıştır.

\subsection{Kullanım yeri stabilitesi}

Kullanım yeri stabilitesi, anizotropik çekme ve şişmelerle yakından ilgilidir. Anizotropik çekme, teğet yöndeki çekmenin radyal yöndeki çekmeye oranıdır. Anizotropik şişme ise teğet yöndeki şişmenin radyal yöndeki şişmeye oranıdır. Kullanım yeri stabilitesinin tayininde radyal ve teğet yönlerdeki çekme ve şişme deneylerine ait değerlerden yararlanılmıştır. $\mathrm{Bu}$ değerler kullanılarak anizotropik çekme ve şişmeler, Kubler (1978) ve Bozkurt vd. (1993)'a göre aşağıdaki eşitliklerle tayin edilmiş tir. Hes aplamada boyuna yöndeki anizotropik çekme ve şişmeler dikkate alınmamıştır.

$$
\begin{aligned}
& A D=T D / R D \\
& A G=T G / R G
\end{aligned}
$$

$\mathrm{Bu}$ eşitlikte; $A D$ ve $A G$, sırasıyla, anizotropik çekme ve şişmedir. $T D$ ve $T G$, teğet yönde, sırasıyla, çekme (\%) ve şişmedir (\%). $R D$ ve $R G$, radyalyönde, sırasılya, çekme (\%) ve şişmedir (\%). 


\subsection{Istatistiksel analiz}

Çalışmaya ilişkin değerler, SPSS (Versiyon 20, 2012) yazilım programında varyans analizi (ANOVA) ve Duncan testi kullanılarak analiz edilmiştir. ANOVA, jeotermal kaynak türünün, kızılçam ve karaçam odun örneklerinin çekme ve şişme özelliği ile kullanım yeri stabilitesi üzerine etkilerinin istatistiksel anlamda güvenilirlik düzeyini belirlemede kullanılmıştır. Etkiler önemli $(p \leq 0.05)$ bulunduğunda, jeotermal kaynaklar aras nndaki homojenlik grupları ve bunların ortalamaları arasındaki anlaml farkliliklar \%95 güven düzeyinde Duncan testiyle belirlenmiştir.

\section{Bulgular ve tartışma}

\subsection{Radyal, teğet ve hacimsel çekme}

Kütahya-Simav'da üç değişik kaynaktan alınan jeotermal sularla emprenyeli kızılçam ve karaçam odun örneklerinden elde edilen radyal, teğet ve hacimsel çekmelere ilişkin istatistik değerlendirmeler Çizelge 1'de verilmiştir.

Kızılçamda, en düşük radyal ve hacims el çekme, Ç-1 için, sırasıyla, \%5.29 ve \%12.00 olurken, en düşük teğet çekme, E-6 için \%7.02 olmuştur. En yüksek teğet ve hacimsel çekme, N-1 için, sırasıyla, \%7.72 ve \%13.17 olurken, en yüksek radyal çekme, E-6 için \%6.25 olmuştur. Test örnekleri kontrol grubu örneklerle karşılaştırıldı̆̆ında, bu üç özellik bakımından, kontrol ile Ç-1 ve E-6 arasında önemli farklilık varken, N-1 ile aras nndaki fark önemli değildir. Aynı şekilde, jeotermal kaynaklar kendi aralarında karşılaştırıldığında, radyal çekmede $\mathrm{N}-1$, Ç-1 ve E-6 aras ında önemli farklılık varken, hacimsel çekmede N-1 ile E-6 aras inda önemli bir fark yoktur. Radyal ve hacimsel çekmede Ç-1 ve E-6 aras indaki farklılık önemliyken, teğet çekmedeki fark önemsizdir. Ayrıca kızılçamda, E-6 radyal çekmeyi N-1 ve Ç-1'e göre arttırmıştır. Ç-1 radyal ve hacimsel çekmeyi N-1 ve E-6'ya göre azaltırken, teğet çekmede E-6'ya göre yaptığı değişiklik gözardı edilebilir. N-1 teğet çekmeyi E-6'ya göre arttırırken, hacimsel çekmede hiçbir değişiklik yapmamıştır.
Karaçamda, en düşük teğet çekme, N-1 için \%5.89 olurken, en düşük radyal ve hacims el çekme, sırasıyla, Ç-1 için \%4.49 ve E-6 için \%10.36 bulunmuştur. En yüksek teğet çekme, Ç-1 için \%6.18 olurken, en yüksek radyal ve hacimsel çekme, N-1 için, sırasıyla \% 4.96 ve \%10.77 olmuştur. Test örnekleri kontrol grubu örneklerle karşılaştırıldığında, bu üç özellik bakımından, kontrol ile N1, Ç-1 ve E-6 arasında önemli farklılıklar vardır. Aynı şekilde, jeotermal kaynaklar kendi aralarında karşılaştırıldığında, bu üç özellik bakımından, N-1 ile Ç-1 ve E-6 arasındaki farklılık önemli çıkarken, Ç-1 ve E-6 arasındaki farklılık önemsiz çıkmıştır. Ayrıca karaçamda, N-1 teğet çekmeyi Ç-1 ve E-6'ya göre azaltmıştır. Ç-1 ve E6 radyal, teğet ve hacimsel çekmede hiçbir değişiklik yapmazken, radyal ve hacimsel çekmeyi N-1'e göre arttırmıştır.

Çalışmamıza ait radyal, teğet ve hacimsel çekme değerleri literatürle karşılaştırıldığında (Bozkurt vd., 1993; Erten ve Sözen, 1996; Bozkurt ve Erdin, 1997; As vd., 2001), literatürde, bu özelliklere ait değerlerin, sırasıly, $\% 3.10$ - \%5.60, \%5.40 - \%8.20 ve \%8.80 - \%13.90 arasinda olduğu görülmüştür. Dolayısıyla, çalışmamızda bulunan radyal, teğet ve hacimsel çekme değerlerinin literatürle uyumlu olduğu söylenebilir.

Bilindiği üzere, bir ağacın çalışma özelliğinin iyi olması, teğet ve radyalyönlerdeki çekme değerleri aras ındaki farkın azalmasına bağlıdır. Diğer bir ifadeyle, teğet ve radyal yönlerdeki çekmeler arasındaki fark ne kadar az olursa, çalışma özelliği de o kadar iyi olur (Kubler,1978; Bozkurt ve ark., 1993). Buna göre, çalışmamıza ilişkin sonuçlar göstermiştir ki, emprenyesiz kontrol örneklerine göre, emprenyeli test örneklerinin radyal, teğet ve hacims el çekmeleri önemli derecede azalmıştır. Bu sonuca göre, genel olarak, jeotermal suların, kızılçam ve karaçam odun örneklerinin radyal, teğet ve hacimsel çekme özelliklerini iyileştirdikleri söylenebilir.

\subsection{Radyal, teğet ve hacimsel şişme}

Kütahya-Simav'da 3 farklı kaynaktan alınan jeotermal sularla emprenyeli kızılçam ve karaçam odun örneklerinde elde edilen radyal, teğet ve hacims el şişmelere ait is tatistik değerlendirmeler Çizelge 2'de verilmiştir.

Çizelge 1. Jeotermal sularla emprenyeli kızılçam ve karaçamda radyal, teğet ve hacims el çekmelere ait ortalama değerler*

\begin{tabular}{|c|c|c|c|c|}
\hline Ağaç türü & Jeotermal kaynak & Radyal çekme (\%) & Teğet çekme (\%) & Hacimsel çekme (\%) \\
\hline \multirow{4}{*}{ Kızılçam } & Kontrol & $6.08( \pm 0.33) \mathrm{a}$ & $7.48( \pm 0.36) \mathrm{d}$ & $13.11( \pm 0.59) \mathrm{f}$ \\
\hline & $\mathrm{N}-1$ & $5.91( \pm 0.31) \mathrm{a}$ & $7.72( \pm 0.36) \mathrm{d}$ & $13.17( \pm 0.65) \mathrm{f}$ \\
\hline & Ç-1 & $5.29( \pm 0.27) b$ & $7.10( \pm 0.38) \mathrm{e}$ & $12.00( \pm 0.40) \mathrm{g}$ \\
\hline & E-6 & $6.25( \pm 0.35) \mathrm{c}$ & $7.02( \pm 0.47) \mathrm{e}$ & $12.83( \pm 0.50) \mathrm{f}$ \\
\hline \multirow{4}{*}{ Karaçam } & Kontrol & $5.52( \pm 0.18) \mathrm{j}$ & $6.94( \pm 0.22) \mathrm{m}$ & $12.20( \pm 0.32) \ddot{0}$ \\
\hline & $\mathrm{N}-1$ & $4.96( \pm 0.22) \mathrm{k}$ & $5.89( \pm 0.15) \mathrm{n}$ & $10.77( \pm 0.28) \mathrm{p}$ \\
\hline & Ç-1 & $4.49( \pm 0.10) 1$ & $6.18( \pm 0.20) \mathrm{o}$ & $10.45( \pm 0.29) \mathrm{r}$ \\
\hline & E-6 & $4.53( \pm 0.14) 1$ & $6.13( \pm 0.17) \mathrm{o}$ & $10.36( \pm 0.28) \mathrm{r}$ \\
\hline
\end{tabular}

*: Ayraç içindekiler standart sapmadır. Aynı harfle gösterilen ortalamalar arasında önemli bir farklılık yoktur.

Çizelge 2. Jeotermal sularla emprenyeli kızılçam ve karaçamda radyal, teğet ve hacimsel şişmelere ait ortalama değerler*

\begin{tabular}{ccccc}
\hline Ağaç türü & Jeotermal kaynak & Radyal şişme $(\%)$ & Teğet şişme $(\%)$ & Hacimsel şişme $(\%)$ \\
\hline \multirow{3}{*}{ Kizılçam } & Kontrol & $6.20( \pm 0.27) \mathrm{a}$ & $9.07( \pm 0.34) \mathrm{c}$ \\
& $\mathrm{N}-1$ & $5.76( \pm 0.47) \mathrm{b}$ & $7.79( \pm 0.38) \mathrm{d}$ & $15.85( \pm 0.32) \mathrm{f}$ \\
& $\mathrm{C}-1$ & $5.08( \pm 0.48) \mathrm{c}$ & $7.20( \pm 0.37) \mathrm{e}$ \\
& $\mathrm{E}-6$ & $5.72( \pm 0.51) \mathrm{b}$ & $7.27( \pm 0.30) \mathrm{e}$ & $14.00( \pm 0.76) \mathrm{g}$ \\
Karaçam & Kontrol & $6.61( \pm 0.18) \mathrm{k}$ & $7.57( \pm 0.18) \mathrm{o}$ \\
& $\mathrm{N}-1$ & $4.15( \pm 0.09) \mathrm{l}$ & $6.76( \pm 0.21) \ddot{\mathrm{o}}$ & $13.41( \pm 0.67) \mathrm{h}$ \\
\hline & $\mathrm{C}-1$ & $4.51( \pm 0.07) \mathrm{m}$ & $7.08( \pm 0.23) \mathrm{p}$ & $14.60( \pm 0.30) \mathrm{s}$ \\
& $\mathrm{E}-6$ & $4.72( \pm 0.11) \mathrm{n}$ & $6.46( \pm 0.16) \mathrm{r}$ & $12.00( \pm 0.19) \mathrm{t}$ \\
\hline
\end{tabular}

\footnotetext{
*: Ayraç içindekiler standart sapmadır. Aynı harfle gösterilen ortalamalar arasında önemli bir farklılık yoktur.
} 
Kızılçamda, en düşük radyal, teğet ve hacimsel şişme, Ç-1 için, sırasıyla, \%5.08, \%7.20 ve \%12.65 olurken, en yüksek değerler, N-1 için, surasıyla, \%5.76, \%7.79 ve $\% 14.00$ olmuştur. Test örnekleri kontrol grubu örneklerle karşılaştırıldığında, bu üç özelliğe ilişkin değerler, kontrol ile üç jeotermal su arasında önemli farklılık göstermiştir. Aynı şekilde jeotermal kaynaklar kendi aralarında karşılaştırıldığında, radyal şişme, sırasıyla, N-1 ve Çaras inda farklılık gösterirken, $\mathrm{N}-1$ ve E-6 arasinda farkl1lik göstermemiştir. Teğet ve hacims el şişme değerleri, N-1 ile Ç-1 ve E-6 aras ında farklılık gösterirken, teğet ş işme E-6 ve Ç-1 arasında farklılık ortaya koymamışır. Ayrıca, kızılçam için, N-1 radyal, teğet ve hacimsel şişmeyi Ç-1 ve E-6'ya göre arttırmıştır. Bu artış, teğet ve hacimsel şişmeler için önemliyken, radyal şişme için, E-6'da önemsiz bulunmuştur.

Karaçamda, en düşük radyal ve hacimsel şişme değerleri, N-1 için, sırasıyla, $\% 4.15$ ve $\% 11.20$ olurken, en düşük teğet şişme, E-6 için, \%6.46 olmuştur. En yüksek teğet ve hacims el şişme değerleri, Ç-1 için, sırasıyla, \%7.08 ve \%12.00 olurken, en yüksek radyal şişme, E-6 için, \% 4.72 olmuştur. Bu üç özelliğe ilişkin değerler, hem kontrol ile jeotermal sular arasinda hem de jeotermal suların kendileri arasında önemli bir farklılık göstermiştir. Ayrıca karaçam için, Ç-1 teğet ve hacims el şişmeyi N-1 ve E-6'ya göre arttırırken, N-1 radyal ve hacims el şişmeyi azaltmıştır. E-6 teğet şişmeyi azaltırken, radyal şişmeyi arttırmıştır.

Çalışmada elde edilen radyal, teğet ve hacimsel şişme değerleri literatür (Erten ve Sözen, 1996) sonuçlariyla karşılaştırıldığında, radyal şişmenin \%5.01 - \%5.75, teğet şişmenin \%7.24 - \%9.36 ve hacimsel şişmenin \%12.83 \%15.46 arasında değiştiği görülmüştür. Buna göre, çalışmamızda bulunan radyal, teğet ve hacimsel şişmelerin, genel olarak, literatürden farklı (düşük) olduğu söylenebilir. $\mathrm{Bu}$ farklılık deneysel materyal ve emprenye işleminden kaynaklanmış olabilir.

Bir ağacın çalışma özelliğinin iyi olması, teğet ve radyal yönlerdeki şişme değerleri arasındaki farkın azalmasına bağlıdır. Diğer bir ifadeyle, teğet ve radyal yönlerdeki genişlemeler arasındaki fark ne kadar az olursa, çalışma özelliği de o kadar iyi olur (Kubler,1978; Bozkurt vd., 1993). Buna göre, çalı̧̧mamıza ilişkin sonuçlar göstermiştir ki, kontrol grubu örneklere göre, bütün test grubu örneklerin radyal, teğet ve hacimsel şişme değerleri önemli derecede azalmıştır. Bu sonuca göre, genel olarak, jeotermal suların, kızılçam ve karaçam örneklerinin radyal, teğet ve hacimsel şişme özelliklerini iyileştirdikleri söylenebilir.

\subsection{Kullanım yeri stabilitesi}

Kütahya-Simav jeotermal sahasında 3 değişik kaynaktan alınan jeotermal sularla emprenyeli kızılçam ve karaçam odun örneklerinde elde edilen kullanım yeri stabilitesine iliş kin is tatis tik değerlendirmeler Çizelge 3'de verilmiştir.

Kızılçamda, anizotropik çekme ve şişmede, en düşük değer, E-6 için, sırasıyla, 1.13 ve 1.28 olurken, en yüksek değerin, Ç-1 için, sırasıyla, 1.35 ve 1.43 olduğu belirlenmiştir. Çekme anizotropis inde kontrol ile jeotermal sular arasında önemli bir farklılık olmasına karşıllk, N-1 ve Ç-1 arasında hiçbir farklılık yokken, E-6 ile diğer iki kaynak arasında önemli farklılık bulunmuştur. Şişme anizotropisinde is e Ç-1 ile hem kontrol hemde N-1 arasında önemli hiçbir farklılık olmamasına karşılık, Ç-1 ve E-6 arasındaki farklılığın önemli, N-1 ve E-6 arasındaki farklılığın önemsiz olduğu görülmüştür. Ayrıca kızılçamda, anizotropik çekmeyi, N-1, E-6'ya göre arttırırken, Ç-1'e göre değişiklik yapmamıştır. Anizotropik şişmeyi ise N-1, Ç-1'e göre azaltıp E-6'ya göre değişiklik yapmazken, Ç-1, E-6'ya göre azaltmıştır.

Karaçamda, anizotropik çekme ve şişmede, en düşük değer, sırasıyla, N-1 için 1.19 ve E-6 için 1.37 bulunurken, en yüksek değerin, sırasıyla, Ç-1 için 1.38 ve N-1 için 1.63 olduğu ortaya konmuştur. Ayrica her iki ağaç için, çekme ve şişme anizotropisi yönünden, hemkontrol ile jeotermal sular arasında hem de jeotermal suların kendi arasında önemli farklılık olduğu tespit edilmiştir. Ayrıca karaçamda, anizotropik çekmeyi, N-1, Ç-1 ve E-6'ya göre azaltırken, Ç1 ve E-6 biribirine göre değ işiklik yapmamıştır. Anizotropik şişmeyi ise N-1 ve Ç-1, E-6'ya göre önemli derecede arttırmıştır. $\mathrm{Bu}$ artış, $\mathrm{N}-1$ 'de Ç-1'dekinden daha fazla olmuştur.

Bir ağaç türünün kullanım yeri stabilitesi, onun, anizotropik çekme ve şişmesiyle yakından ilgilidir. Dolayısıyla, kullanım yerindeki stabilitenin iyi olmas1, anizotropik çekme ve şişmenin azalmasına bağlıdır. Diğer bir ifadeyle, teğet yöndeki çekme ve şişmenin radyal yöndeki, sırasıyla, çekme ve şişmeye oranı ne kadar az olursa, kullanım yeri stabilitesi de o kadar iyi olur (Kubler, 1978; Bozkurt vd., 1993). Buna göre, çalışmamıza ilişkin sonuçlar göstermiştir ki, kontrolörneklerine göre, bütün test örneklerinin anizotropik şişme değeri karaçamda artıp kızılçamda azalmasına karşılık, anizotropik çekme değeri, kızılçam için, E-6'da azalıp N-1 ve Ç-1'de artarken, karaçam için, N-1'de azalıp Ç-1 ve E-6'da artmıştır. Bu sonuca göre, genel olarak, E-6 kaynağının, kızılçam ve karaçam odun örneklerinin kullanım yeri stabilitesini iyileştirdiği söylenebilir.

Çizelge 3. Jeotermal sularla emprenyeli kızılçam ve karaçam odunlarının kullanım yeri stabilitesine ait ortalamadeğerler

\begin{tabular}{|c|c|c|c|}
\hline \multirow{2}{*}{ Ağaç türü } & \multirow{2}{*}{ Jeotermal kaynak } & \multicolumn{2}{|c|}{ Kullanım yeri stabilitesi* } \\
\hline & & Anizotropik çekme & Anizotropik şişme \\
\hline \multirow{4}{*}{ Kızılçam } & Kontrol & $1.23( \pm 0.08) \mathrm{a}$ & $1.47( \pm 0.10) \mathrm{d}$ \\
\hline & N-1 & $1.31( \pm 0.10) \mathrm{b}$ & $1.36( \pm 0.11) \mathrm{ef}$ \\
\hline & Ç-1 & $1.35( \pm 0.07) b$ & $1.43( \pm 0.15) \mathrm{de}$ \\
\hline & E-6 & $1.13( \pm 0.09) \mathrm{c}$ & $1.28( \pm 0.10) \mathrm{f}$ \\
\hline \multirow{4}{*}{ Karaçam } & Kontrol & $1.26( \pm 0.04) \mathrm{g}$ & $1.15( \pm 0.03) \mathrm{j}$ \\
\hline & $\mathrm{N}-1$ & $1.19( \pm 0.06) \mathrm{h}$ & $1.63( \pm 0.06) \mathrm{k}$ \\
\hline & Ç-1 & $1.38( \pm 0.05)_{1}$ & $1.57( \pm 0.06) 1$ \\
\hline & E-6 & $1.35( \pm 0.05)_{1}$ & $1.37( \pm 0.04) \mathrm{m}$ \\
\hline
\end{tabular}

*: Ayraç içindekiler standart sapmadır. Aynı harfle gösterilen ortalamalar arasında önemli bir farklılık yoktur. 
$\mathrm{Bu}$ çalışmaya dair anizotropik çekme ve şişme değerleri literatürle karşılaştırıldığında, literatürde, bu değerlerin, sırasıyla, $1.39-1.74$ ve $1.45-1.63$ arasında değiștiği görülmüştür (Bozkurt vd. 1993; Erten ve Sözen, 1996; Bozkurt ve Erdin 1997; As vd. 2001). Buna göre, çalışmamızda bulunan anizotropik çekme ve şişmelerin, diğer deyişle, kullanım yeri stabilitesinin, genel olarak, literatürden biraz düşük olduğu söylenebilir. Bu farklılık, kullanılan deneysel materyal ve emprenye işleminden kaynaklanmış olabilir.

\section{Sonuç ve öneriler}

Bu çalışmada, elde edilen sonuçlar ve yapılan öneriler, aşağıda verilmiş tir:

Karaçam için, radyal, teğet ve hacims el şişme değerleri, her üç kaynakta önemli farklılık gösterirken, çekme değerleri N-1'de farklı olup Ç-1 ve E-6'da hiçbir farklılık göstermemiştir. Ayrıca anizotropik çekme değerleri N-1'de farklı olup Ç-1 ve E-6'da farksız olmasına karşın, anizotropik şişme değerleri ise her üç kaynakta da farklılık göstermiştir.

Kızılçam için, radyal çekme değerleri her üç kaynakta farklılık gösterirken, şişme değerleri N-1 ve E-6'da bir farklılık ortaya koymamıştır. Teğet çekme ve şişme değerleri N-1'de farklı olup Ç-1 ve E-6'da farks ız olmasina karşılık, hacims el çekme değerleri Ç-1'de farklı olup N-1 ve E-6'da farksız iken, şişme değerleri her üç kaynakta bir farklılık göstermemiş tir. Ayrıca anizotropik çekme değerleri E-6'da farklı olup N-1 ve Ç-1'de farksız bulunmuşken, anizotropik şişme değerleri Ç-1 ve E-6'da farklı olup N-1 ve Ç-1'de birbirine yakın değerler vermiştir.

Bir ağaç malzemede radyal, teğet ve hacimsel çekme ve şişme değerleri, onun, çalışma özelliğini doğrudan etkilerken, anizotropik çekme ve șișme değerlerinin ise kullanım yeri stabilitesiyle çok yakından ilgili olduğu bilinmektedir. Dolayısıyla, çalışma özelliğinin iyi/düşük olması, teğet ve radyal yöndeki çekme değerleri arasındaki farkın azalmasına bağlı iken, aynı şekilde, teğ et ve radyal yöndeki şişme değerleri arasındaki farkın azalmasına da bağlıdır. Kullanım yeri stabilitesinin iyi olması ise anizotropik çekme ve şişme değerlerinin düşük olmasına bağlıdır. Buna göre, Kütahya-Simav yöresi jeotermal suları, kızılçam ve karaçam odun örneklerinde, radyal ve teğet yöndeki çekme ve şişme değerleri arasındaki farkları, emprenyesiz kontrol örneklerine göre önemli derecede azaltmıştır. Bu azalmalar, diğ erlerine göre E-6'da daha fazla olmuştur. Diğer yandan, kızılçam ve karaçam odun örneklerinin çekme ve şişme bakımından kullanım yeri stabiliteleri E-6'da azalıp Ç-1'de artmıştır. N-1'de ise kızılçamın kullanım yeri stabilitesi çekme bakımından artıp şişme bakımından azalırken, karaçamda tam tersi bir durum sergilenmiştir.

Radyal ve teğet yöndeki çekme ve şişmeler arasındaki farkların azalması, çalışma özelliğinin iyileştiğini gösterirken, anizotropik çekme ve şişmenin düşük olmas1 ise kullanım yeri stabilitesinin iyileştiğini ortaya koymaktadır. Buna göre, çekme ve şişme özelliği ile kullanım yeri stabilitesinin önemli olduğu mekânlar için, kızılçam ve karaçam odunlarının, radyal biçmeye ilaveten, E-6 jeotermali ile emprenye edilmesi, N-1 ve Ç-1'e göre daha iyi sonuçlar verebilir.

\section{Teşekkür}

$\mathrm{Bu}$ çalışma, tasarımı ve geliştirilmesi Ahmet Ali VAR tarafindan önerilip denetlenen ve SDU BAP 3365-YL1-12 numaralı proje ile desteklenip SDÜ Fen Bilimleri Enstitüsü'nde İbrahim KARDAŞ tarafindan hazırlanan Yüksek Lisans tezinin bir bölümünün özetidir. Yazarlar, finansal ve jeotermal kaynak destekleri için, sırasıyla, SDU BAP Koordinasyon Birimi ile Eynal, Çitgöl ve Naşa jeotermal tes is lerine teşekkür ederler.

\section{Kaynaklar}

Akkuş, I., Akıllı, H., Ceyhan, S., Dilemre, A., Tekin, Z., 2005. Türkiye Jeotermal Kaynakları Envanteri. MTA Genel Müdürlüğü Yayınları, Envanter Serisi-201, Ankara.

As, N., Koç, K.H., Doğu, D., Atik, C., Aksu, B., Erdinler, S., 2001. Türkiye'de yetişen endüstriyel öneme sahip ağaçların anatomik, fiziksel, mekanik ve kimyasal özellikleri. İ.Ü. OF Dergisi, 51(1): 71-88.

Bal, B.C., Bektaş, İ., Kaymakçı, A., 2012. Toros sedirinde genç odun ve olgun odunun bazı fiziksel ve mekanik özellikleri. KSU Mühendislik Bilimleri Dergisi, 15(2): 17-27.

Bayram, F., 1999.. Simav Jeotermal Alanının Hidrojeoloji İncelemesi. Doktora Tezi, SÜ Fen Bilimleri Enstitüsü, Konya.

Bozkurt, A.Y., Goker, Y., Erdin, N., 1993. Emprenye Tekniği. İ̈̈ Yayınları No: 3779/425, İstanbul.

Bozkurt, A.Y., Erdin, N., 1997. Ağaç Teknolojisi. IÜ Yayınları No: 3998/445, İstanbul.

Bozkurt, Y., Göker, Y., Kurtoğlu, A., 1990. Siğla odununun fiziksel ve mekanik özellikleri. İ̈̈ Orman Fakültesi Dergisi, 40(2): 1-18.

Çağlar, K.O., 1948. Turkey's mineral waters and hot springs (in Turkish). Publications of Mineral Research and Exploration of Turkey (MTA), Ankara.

Erdoğmuş, B., Toksoy, M., Özerdem, B., Aksoy, N., 2006. Economic assessment of geothermal district heating systems: A case study of Balcova-Narlidere, Turkey. Energy Build., 38: 1053-1059.

Erişen, B., Akkus, I., Uygur, N., Kocak, A., 1996. Türkiye Jeotermal Kaynakları Envanteri. MTA Genel Müdürlüğü Yayınları, Ankara.

Erten, P., Sözen, M.R., 1996. Halep çamı (Pinus halepansis Mill.) odunun fiziksel ve mekaniksel özelliklerinin belirlenmesi. İç Anadolu Ormancılık Araştırma Müdürlüğü, 268:1-40.

Genç, A., 2013. Afyonkarahisar Ömer-Gecek Jeotermal Kaynaklarında Emprenye Maddelerinin ve $\mathrm{Bu}$ Kaynaklarla İşlem Görmüş Ahşabın Bazı Özelliklerinin İncelenmesi. Yüksek Lisans Tezi, SDÜ, Fen Bilimleri Enstitüsü, Isparta.

Gürü, M., 2005. Jeotermal enerji kaynaklarının değerlendirilmesi. Çevreye Genç Bakış, 7.

Usta, İ., Guray, A., 2000. Korsika çamının (Pinus nigra var. mantima) daralma ve genişleme özelliklerinin karşılaştırılması. Turk J Agric For., 24:461-464.

Kantay, R., 1993. Kereste Kurutma ve Buharlama. Ormancılık Eğitim ve Kültür Vakfi, Yayın No: 6, İstanbul. 
Kantay, R., Güngör, N. M., 2009. Masif ahşap Döşemelerde duvar dibi genişleme boşluklarını etkileyen faktörler ve hesaplanmasi. İ̈̈ Orman Fakültesi Dergisi, 59(1): 93103.

Karademir, E., 2012. Jeotermal akışkanlarla emprenye edilen ahşabın performansı: Uşak yöresi örneği. Yüksek Lisans Tezi, Süleyman Demirel Üniversitesi, Fen Bilimleri Enstitüsü, Isparta.

Kubler, H., 1978. Buharlanmış ağaç malzemenin özellikleri, İ̈̈ Orman Fakültesi Dergisi, 28(1): 231-240.

Mutlu, M. A., 2004. Jeotermal enerji ve Türkiye'deki durumu, Dünya'da ve Türkiye'de Enerji Potansiyeli ve Enerji Politikaları Konferans Notları www.turkocag1.org.tr/toa/grup-enerji, Erişim: 21 Ocak 2007.

Özalp, M., Ordu, M., 2010. Kereste kurutmada kullanılan enerji kaynağının maliyete etkileri. Dumlupınar Üniv. Fen Bilimleri Enstitüsü Dergisi, 22: 99-108.

Oktu, G., 1984. Hydrological investigation of Eynal and Çitgöl-Naşa (Simav) Hot Springs [in Turkish]. Publications of Mineral Research and Exploration of Turkey (MTA), Ankara.

Özgener, L., Hepbaşl1, A., Dincer, İ., 2006. Performance investigation of two geothermal dis trict heating systems for building applications: Energy analysis. Energy and Buildings, 38:286-292.
TS EN 47, 2011. Ahşap koruma - Ev teke böceği larvalarına karşı zehirlilik değerlerinin tayini (laboratuvar metodu). TSE, Ankara.

TS 4083, 1983. Odunda radyal ve teğet doğrultuda çekmenin tayini. TSE, Ankara

TS 4084, 1983. Odunda radyalve teğ et doğrultudaşişmenin tayini. TSE, Ankara.

TS 4085, 1983. Odunda hacimsel çekmenin tayini. TSE, Ankara.

TS 4086, 1983. Odunda hacimsel şişmenin tayini. TSE, Ankara.

Var, A.A., 2009. Quantative of potential wood preservatives in geothermal fluids and their suitableness for wood impregnation treatment. SDU Faculty of Forestry Journal, 1:184-197.

Var, A.A., Yalçın, M., Şen, S., Taşçığlu, C., 2012. Antifungal activity of geothermal fluids from different regions of Turkey. Biores ources, 7(3):4226-4236.

Var, A.A., Göncü, D., Karsantı̈zü, F., 2013. Investigation of absorption, retention and swelling in Izmir-Doğanbey geothermal waters-treated pine wood (Pinus brutia Ten.). SDU Faculty of Forestry Journal, 14:127-133.

Var, A.A., Genç, A., Kardaş, I., 2014. Investigation of some properties of Afyonkarahisar-Omer-Gecek-Gazligöl geothermal waters-impregnated Crimean pine ( $P$. nigra Arnold.) and Turkish red pine ( $P$. brutia Ten.) sapwoods. SDU Faculty of Forestry Journal, 15:114122. 